\title{
Pulmonary function in coal workers with Caplan's syndrome and non-rheumatoid complicated. pneumoconiosis
}

\author{
KIMON CONSTANTINIDIS, A W MUSK, ${ }^{1} \mathrm{~J}$ P R JENKINS, AND G BERRY \\ From the Medical Research Council, Pneumoconiosis Unit, Llandough Hospital, Penarth, \\ South Glamorgan, UK
}

Constantinidis, K, Musk, A W, Jenkins, J P R, and Berry, G (1978). Thorax, 33, 764-768. Pulmonary function in coal workers with Caplan's syndrome and non-rheumatoid complicated pneumoconiosis. This retrospective study compares the pulmonary function of 24 coal workers with Caplan's syndrome with that of 36 subjects with non-rheumatoid progressive massive fibrosis (PMF). Allowing for differences in radiographical category, age, years worked underground, and smoking, obstruction to air flow as reflected in the one-second forced expiratory volume, the vital capacity, and the ratio of residual volume to total lung capacity, 'was significantly less in subjects with Caplan's syndrome. No significant differences in transfer factor were found. These findings may be explained by the different pathological features of the two entities. Selection bias does not appear to be responsible for the differences observed between the groups, but studies designed to eliminate this would be desirable.

Caplan's syndrome (Caplan, 1953) is customarily distinguished from non-rheumatoid complicated pneumoconiosis or progressive massive fibrosis (PMF) by its characteristic radiographical appearance (with multiple rounded opacities tending to be situated more peripherally throughout the lungs, individually smaller in size than the single opacities of PMF, and usually on a background of less severe simple pneumoconiosis) and by the coexistence of arthritis or other clinical manifestations of rheumatoid disease or the presence of circulating rheumatoid factor (Miall et al, 1953). This study was designed to investigate the different effects of the presence of large opacities on lung function between Caplan's syndrome and PMF and to relate these differences to knowledge of the pathology of complicated coal workers' pneumoconiosis. Although Caplan's syndrome often occurs in the presence of lesser categories of simple pneumoconiosis (Caplan, 1953), simple pneumoconiosis per se has a negligible effect on conventional tests of pulmonary function (Carpenter $e t$ al, 1956; Morgan et al, 1972; Seaton et al, 1972) so that differences in function between subjects with Caplan's syndrome and PMF should reflect ${ }^{1}$ Recipient of a fellowship in clinical sciences (epidemiology) from the
National Health and Medical Research Council of Australia. the differing effects of the superimposed large opacities.

\section{Methods}

Coal workers with complicated pneumoconiosis $\underset{x}{x}$ were selected retrospectively on the basis of the appearance of their chest radiographs from referrals to the pneumoconiosis research unit by the Cardiff Pneumoconiosis Medical Panel or by general practitioners over the ten year period to 웅 June 1977. Caplan's syndrome was distinguished $D$ from PMF by the presence of characteristic radiographical appearances, clinical evidence of rheu- N matoid disease, and/or positive serology for rheumatoid factor (Rose-Waaler differential ag- $\tilde{N}$ glutination titre $\geqslant 1 / 32$ ). Twelve subjects in each $\underset{\omega}{ }$ of the categories A, B, and C with PMF and 24 subjects with Caplan's syndrome (8 with category 0 A, 12 with B, and 4 with C) were studied.

\section{RADIOGRAPHS}

Plain posteroanterior chest radiographs were taken on the day of the performance of pulmonary function tests. Routine procedure required $74 \mathrm{KV}$, $\stackrel{\mathbb{\triangle}}{\AA}$ $40 \mathrm{mAs}$ for $0.8 \mathrm{~s}$. The full-sized films were read jointly by two readers, and an agreed classification 
was made (ILO U/C, 1971). They were then read independently by a third reader who confirmed the joint readings.

\section{PULMONARY FUNCTION}

Forced expiratory volume in one second $\left(\mathrm{FEV}_{1}\right)$ and forced vital capacity (FVC) were measured with digital bellows spirometer (McDermott and McDermott, 1977). Total lung capacity (TLC), vital capacity (VC), and residual volume (RV) were measured by the helium dilution technique (Cotes, 1975). Transfer factor (T1), transfer factor per unit of alveolar volume (KCO), the diffusing capacity of the pulmonary capillary membrane $(\mathrm{Dm})$, and the volume of blood in the alveolar capillaries $(\mathrm{Vc})$ were measured by the single breath carbon monoxide method (Cotes, 1975) using a Respirameter Mark IV (P K Morgan).

\section{RESPIRATORY SYMPTOMS}

The presence of bronchitis and dyspnoea and the smoking and occupational histories were obtained from the 1965 British Medical Research Council questionnaire. Bronchitis and dyspnoea were graded according to the Medical Research Council report (MRC, 1965).

\section{Results}

The clinical and radiological characteristics of the subjects from the six categories determined by the type of disease (PMF or Caplan's syndrome) and size of opacities (A, B, or C) were comparable except that those with Caplan's syndrome were on average younger, less dyspnoeic, and had less profusion of small opacities than the PMF cases (table 1).
Table 1 Clinical and radiographical characteristics of groups

\begin{tabular}{|c|c|c|c|c|c|c|}
\hline \multirow{3}{*}{$\begin{array}{l}\text { Radiographical category } \\
\text { No of subjects } \\
\text { Mean age }\end{array}$} & \multicolumn{3}{|c|}{ Caplan's syndrome } & \multicolumn{3}{|l|}{$P M F$} \\
\hline & $\mathbf{A}$ & $\mathbf{B}$ & C & $\mathbf{A}$ & $\mathbf{B}$ & $\mathbf{C}$ \\
\hline & $\begin{array}{c}8 \\
50 \cdot 5\end{array}$ & $\begin{array}{l}12 \\
54 \cdot 8\end{array}$ & $\begin{array}{c}4 \\
57 \cdot 5\end{array}$ & $\begin{array}{l}12 \\
57 \cdot 1\end{array}$ & $\begin{array}{l}12 \\
58 \cdot 2\end{array}$ & $\stackrel{12}{56 \cdot 3}$ \\
\hline Mean years underground & $27 \cdot 9$ & $29 \cdot 3$ & $32 \cdot 5$ & 33.9 & $29 \cdot 6$ & $26 \cdot 0$ \\
\hline Mean dyspnoea grade & $2 \cdot 5$ & $2 \cdot 6$ & $\mathbf{3} \cdot \mathbf{3}$ & $3 \cdot 3$ & $3 \cdot 4$ & $3 \cdot 8$ \\
\hline Mean bronchitis grade & 0.5 & 0.8 & $1 \cdot 2$ & $1 \cdot 1$ & 0.7 & $1 \cdot 3$ \\
\hline No of current smokers & 8 & 8 & $2 *$ & 10 & 8 & 10 \\
\hline \multicolumn{7}{|c|}{ Background of small opacities: } \\
\hline $\begin{array}{l}\text { Mean profusion } \\
\text { Type: No of subjects }\end{array}$ & $2 / 3$ & $2 / 3$ & $2 / 1$ & $2 / 3$ & $3 / 2$ & $2 / 3$ \\
\hline p & 2 & 2 & 1 & 6 & 3 & 1 \\
\hline $\mathbf{q}$ & 3 & $\overline{8}$ & 3 & 6 & 9 & 11 \\
\hline $\mathbf{r}$ & 3 & 1 & 0 & 0 & 0 & 0 \\
\hline s & 0 & 1 & 0 & 0 & 0 & 0 \\
\hline
\end{tabular}

*Smoking history not obtained on one subject.

The mean values of pulmonary function, corrected to age 55 years and height $1.70 \mathrm{~m}$ (Cotes, 1975) are shown in table 2 for each group of subjects. This table suggests that subjects with Caplan's syndrome have less obstruction to airflow as measured by spirometry and lung volumes and a tendency to a larger transfer factor than subjects with PMF of the same radiological category. The statistical significance of these apparent differences was explored by multiple regression technique. There was no evidence that the differences in lung function between Caplan's syndrome and PMF were dependent on the category of pneumoconiosis since there was no significant interaction between category and type of disease for any index of pulmonary function. The data are therefore consistent with the differences in lung function between Caplan's syndrome and PMF being independent of categories $\mathrm{A}, \mathrm{B}$, or $\mathrm{C}$.

The mean differences in pulmonary funciion

Table 2 Mean values of lung function indices*

\begin{tabular}{|c|c|c|c|c|c|c|c|}
\hline & \multicolumn{3}{|c|}{ Caplan's syndrome } & \multicolumn{3}{|l|}{$P M F$} & \multirow{2}{*}{$\begin{array}{l}\text { Within group } \\
\text { standard } \\
\text { deviation }\end{array}$} \\
\hline & $\boldsymbol{A}$ & $\boldsymbol{B}$ & $C$ & $A$ & $\boldsymbol{B}$ & $C$ & \\
\hline No of subjects & $8 \dagger$ & 12 & 4 & $12 \ddagger$ & $12 \S$ & $12 \|$ & \\
\hline $\mathrm{FEV}_{1}(\mathrm{l})$ & $2 \cdot 62$ & $2 \cdot 24$ & $2 \cdot 28$ & 1.93 & $1 \cdot 76$ & $1 \cdot 14$ & 0.59 \\
\hline FVC (1) & $3 \cdot 85$ & $3 \cdot 71$ & 3.45 & $3 \cdot 13$ & 3.08 & $2 \cdot 63$ & 0.68 \\
\hline FEV/FVC (\%) & $67 \cdot 9$ & $59 \cdot 8$ & $64 \cdot 2$ & $58 \cdot 7$ & $54 \cdot 1$ & $42 \cdot 5$ & $11 \cdot 7$ \\
\hline TLC (1) & $6 \cdot 56$ & $6 \cdot 27$ & 5.89 & $6 \cdot 15$ & $5 \cdot 69$ & $5 \cdot 50$ & 0.93 \\
\hline VC (I) & $4 \cdot 18$ & $3 \cdot 84$ & $3 \cdot 71$ & $3 \cdot 51$ & $3 \cdot 32$ & 2.97 & 0.67 \\
\hline RV (1) & $2 \cdot 33$ & $2 \cdot 39$ & $2 \cdot 15$ & $2 \cdot 67$ & $2 \cdot 43$ & $2 \cdot 54$ & 0.77 \\
\hline RV/TLC (\%) & $35 \cdot 0$ & $38 \cdot 0$ & $37 \cdot 4$ & $42 \cdot 4$ & $44 \cdot 4$ & $47 \cdot 1$ & $9 \cdot 8$ \\
\hline $\mathrm{T} 1\left(\mathrm{mmol} \mathrm{min}^{-1} \mathrm{kPa}^{-1}\right)$ & $8 \cdot 53$ & $7 \cdot 07$ & 6.93 & $7 \cdot 36$ & $6 \cdot 64$ & $6 \cdot 21$ & $2 \cdot 0$ \\
\hline $\mathrm{KCO}\left(\mathrm{mmol} \mathrm{min}^{-1} \mathrm{kPa}^{-1} 1^{-1}\right)$ & $1 \cdot 35$ & $1 \cdot 21$ & $1 \cdot 20$ & $1 \cdot 26$ & $1 \cdot 21$ & $1 \cdot 12$ & $0 \cdot 31$ \\
\hline $\mathrm{Dm}\left(\mathrm{mmol} \mathrm{min}^{-1} \mathrm{kPa}^{-1} 1^{-1}\right)$ & $16 \cdot 2$ & $12 \cdot 0$ & $13 \cdot 0$ & $15 \cdot 3$ & $12 \cdot 7$ & $10 \cdot 3$ & $5 \cdot 1$ \\
\hline $\mathrm{Vc}(\mathrm{ml})$ & $60 \cdot 4$ & $55 \cdot 6$ & 40.9 & $53 \cdot 1$ & $36 \cdot 6$ & $45 \cdot 0$ & $25 \cdot 6$ \\
\hline
\end{tabular}

*Standardised to age 55 years and height $1 \cdot 7 \mathrm{~m}$.

†Only 6 subjects for Dm and Vc.

†Only 11 subjects for Dm and Vc.

\$Only 11 subjects for Dm.

IOOnly 11 subjects for Vc. 
Table 3 Effects of disease type and category. (Estimate of effect ${ }^{1} \pm S E$ )

\begin{tabular}{|c|c|c|c|}
\hline & Caplan & Category $B$ & Category $C$ \\
\hline $\begin{array}{l}\text { FEV1 (l) } \\
\text { FVC (1) } \\
\text { FEV/FVC (\%) } \\
\text { TLC (1) } \\
\text { VC (1) } \\
\text { RV (1) } \\
\text { RV/TLC }(\%) \\
\text { T1 }\left(\mathrm{mmol} \mathrm{min}^{-1} \mathrm{kPa}^{-1}\right) \\
\text { KCo }\left(\mathrm{mmol} \mathrm{min}^{-1} \mathrm{kPa}^{-1} 1^{-1}\right) \\
\text { Dm }\left(\mathrm{mmol} \mathrm{min}^{-1} \mathrm{kPa}^{-1} 1^{-1}\right) \\
\text { Vc (ml) }\end{array}$ & $\begin{array}{c}0 \cdot 70 \pm 0 \cdot 16^{* * *} \\
0 \cdot 70 \pm 0 \cdot 18^{* * *} \\
10 \cdot 40 \pm 3 \cdot 20^{* *} \\
0 \cdot 48 \pm 0 \cdot 25 \\
0 \cdot 62 \pm 0 \cdot 18^{* *} \\
-0 \cdot 23 \pm 0 \cdot 20 \\
-7 \cdot 50 \pm 2 \cdot 60^{* *} \\
0 \cdot 75 \pm 0 \cdot 54 \\
0 \cdot 05 \pm 0 \cdot 08 \\
0 \cdot 60 \pm 1 \cdot 40 \\
10 \cdot 10 \pm 7 \cdot 10\end{array}$ & $\begin{array}{l}-0.28 \pm 0.18 \\
-0.09 \pm 0.20 \\
-6.50 \pm 3.60 \\
-0.39 \pm 0.28 \\
-0.26 \pm 0.20 \\
-0.11 \pm 0.23 \\
2.50 \pm 2.90 \\
-1.05 \pm 0.61 \\
-0.09 \pm 0.09 \\
-3.40 \pm 1.60^{*} \\
-11 \cdot 10 \pm 8.10\end{array}$ & $\begin{array}{l}-0.67 \pm 0.20^{* *} \\
-0.48 \pm 0.23^{*} \\
-12.90 \pm 4.00^{* *} \\
-0.64 \pm 0.31^{*} \\
-0.53 \pm 0.22^{*} \\
-0.13 \pm 0.26 \\
4 \cdot 10 \pm 3 \cdot 20 \\
-1 \cdot 33 \pm 0.68 \\
-0.15 \pm 0.10 \\
-4.60 \pm 1.80^{*} \\
-10.90 \pm 9.10\end{array}$ \\
\hline
\end{tabular}

${ }^{*} \mathrm{P}<0.05 ; \quad *{ }^{*} \mathrm{P}<0.01 ; \quad * *{ }^{*} \mathrm{P}<0.001$.

${ }^{1}$ For instance, on average the FEV 1 of Caplan cases was 0.701 higher than of PMF cases after allowing for differences between categories; and categories $B$ and $C$ are 0.28 and 0.671 respectively less than category $A$ after allowing for difference between disease types.

between subjects with Caplan's syndrome and those with PMF (measured as "effect" of disease type) and between categories of disease (measured as "effect" of disease category) are shown in table 3. Pulmonary function in subjects with Caplan's syndrome was significantly different from those with PMF for $\mathrm{FEV}_{1}, \mathrm{FVC}, \mathrm{FEV} / \mathrm{FVC}, \mathrm{VC}$, and $\mathrm{RV} / \mathrm{TLC}$. There was a significant effect of disease category for $\mathrm{FEV}_{1}, \mathrm{FVC}, \mathrm{FEV} / \mathrm{FVC}, \mathrm{TLC}, \mathrm{VC}$, and Dm.

The associations of the lung function indices with type and category of disease were further explored for modification of effect by age, years worked underground, smoking, and profusion of small opacities. FVC was negatively correlated with age in addition to the reference effect of age; allowing for this additional age effect reduced the Caplan effect from 0.70 1 to 0.62 1. RV/TLC was positively correlated with age in addition to the reference effect; allowing for this the Caplan effect is still significant $(-5.9 \pm 2.5 \%)$. The average TLC for current smokers was 0.681 greater than for the remainder and allowing for this the Caplan effect was reduced to 0.451 . Thus it is seen that allowing for these variables made no difference to the interpretations provided by table 3 . Since the variables elaborated in table 1 may constitute confounding factors or reflect selection bias we additionally examined the way in which differences in the prevalence of dyspnoea and bronchitis would affect the size of the effects in table 3 attributable to disease type and category. Allowing for the combined effects on pulmonary function results of age (above the reference effect), years underground, profusion of small opacities, and smoking, together with dyspnoea and bronchitis, resulted in a reduction of the magnitude of the Caplan effect, but the differences between Caplan's syndrome and PMF remained statistically significant for $\mathrm{FEV}_{1}, \mathrm{FVC}, \mathrm{FEV} / \mathrm{FVC}$ (table 4).

The pattern of functional abnormalities associ-
Table 4 Effects of disease type after allowing for multiple variables and factors ${ }^{1}$. (Estimate of effect $\pm S E$ )

\begin{tabular}{lc}
\hline & Caplan effect \\
\hline FEV $^{1}(1)$ & $0 \cdot 57 \pm 0 \cdot 19 * *$ \\
FVC (l) & $0 \cdot 53 \pm 0 \cdot 21^{*}$ \\
FEV/FVC (\%) & $8 \cdot 20 \pm 3 \cdot 90^{*}$ \\
TLC (l) & $0 \cdot 37 \pm 0 \cdot 27$ \\
VC (l) & $0 \cdot 39 \pm 0 \cdot 21$ \\
RV (l) & $-0 \cdot 05 \pm 0 \cdot 22$ \\
RV/TLC (\%) & $-3 \cdot 50 \pm 2 \cdot 80$ \\
T1 (mmol $\left.\mathrm{min}^{-1} \mathrm{kPa}^{-1}\right)$ & $0 \cdot 05 \pm 0 \cdot 61$ \\
KCo (mmol min & $-0 \cdot 05 \pm 0 \cdot 10$ \\
Dm (mmol $\left.\mathrm{min}^{-1} \mathrm{kPa}^{-1} \mathrm{1}^{-1}\right)$ & $-0 \cdot 60 \pm 1 \cdot 60$ \\
Vc (ml) & $-2 \cdot 00 \pm 8 \cdot 30$ \\
\hline
\end{tabular}

'Caplan effect after allowing for effects of age (above the reference effect of age), years spent underground, profusion of small opacities, smoking habits, dyspnoea, and bronchitis.

${ }^{*} \mathrm{P}<0.05 ; *^{*} \mathrm{P}<0.01$.

ated with Caplan's syndrome in comparison with PMF is indicative of less obstruction to airflow as indicated by higher values of $\mathrm{FEV}_{1}, \mathrm{FVC}, \mathrm{VC}$, FEV/FVC, and lower values of RV/TLC. There is no evidence of less disturbance of gas transfer in Caplan's subjects. The differences in $\mathrm{FEV}_{1}$, FVC, and FEV/FVC persist when maximum adjustment is made for possible confounding variables and selection bias.

\section{Discussion}

Previous studies (Gilson et al, 1955; Cochrane and Higgins, 1961; Hyatt et al, 1964) have shown that differences in pulmonary function exist between categories of complicated pneumoconiosis, and we found similar trends that were statistically significant for $\mathrm{FEV}_{1}, \mathrm{FVC}, \mathrm{FEV} / \mathrm{FVC}$, TLC, Vc, and $\mathrm{Dm}$. In addition, however, the results show that our subjects with Caplan's syndrome had a larger $\stackrel{2}{\mathbb{D}}$ vital capacity and less airflow obstruction than $\varrho$ those with PMF of the same radiographical category. There may be several reasons for this. 
(1) PMF is predominantly situated in the upper zones and occurs more centrally in the lung (Kilpatrick et al, 1954). Resulting distortion of the adjacent large airways that may result in obstruction to air flow is likely to be greater than in Caplan's syndrome, where the lesions tend to be distributed throughout the lung in more peripheral locations, away from the central structures (Caplan, 1953).

(2) The lesions in PMF affect the adjacent lung to a greater extent than in Caplan's syndrome; scar emphysema is more apparent in association with PMF lesions than with Caplan's lesions (Gough et al, 1955).

(3) On whole lung sections PMF is usually accompanied by more extensive focal emphysema in the lung than is Caplan's syndrome. This may be independent of the number of coal nodules that are present. Although category of simple pneumoconiosis has little effect on pulmonary function Ryder et al (1970) have shown that the extent of focal emphysema on whole lung sections is related to the degree of premortem ventilatory impairment. However, differences in the extent of emphysema between subjects in this study do not appear a likely explanation in view of the similarities in gas transfer between the groups.

(4) The lesions in Caplan's syndrome tend to be small and multiple, and the opacities in PMF tend to be large and single. The volume occupied by five separate lesions each of $1 \mathrm{~cm}$ diameter is $2.6 \mathrm{ml}$, and a single spherical lesion of $5 \mathrm{~cm}$ diameter occupies a volume of $65.4 \mathrm{ml}$. Both appearances would radiographically be at the upper limit of category A complicated pneumoconiosis, which depends only on the combined diameter of the lesions-a linear dimension. The discrepancy for categories $B$ and $C$, that are identified on an area basis, would be less. This volume effect may contribute to the differences in VC observed.

(5) It is conceivable that selection bias in a study of this design could contribute to the differences in pulmonary function between the groups if there was a tendency for subjects with Caplan's syndrome to be referred for study on the basis of the appearance of their routine chest radiographs or the onset of arthritic symptoms and subjects with PMF because of respiratory symptoms. In our analysis we stratified the data by radiographical category of complicated pneumoconiosis, and we examined the effects of the presence of bronchitis and dyspnoea on the results, although bronchitis and dyspnoea may be regarded as manifestations of disease rather than as causes of changes in pulmonary function. It is not surprising that the Caplan effect was reduced by allowing for differ- ences between the groups in prevalence of these respiratory symptoms. Despite this adjustment, evidence of airflow obstruction remained significantly less in the subjects with Caplan's syndrome. This suggests that bias due to the selection of subjects with PMF because of the presence of respiratory symptoms does not account for the differences in the results. The evidence does not indicate that the possibility of selection bias should alter our interpretations of the differences in pulmonary function between subjects with Caplan's syndrome and subjects with PMF.

The results of this study suggest that in coal workers with complicated pneumoconiosis the magnitude of impairment of pulmonary function is less in subjects with Caplan's syndrome than in subjects with PMF of the same radiological category. Several explanations are offered for this, but the implication is that the current radiographical classification of complicated pneumoconiosis excludes some of the information that is required.

We are grateful to Dr J E Cotes for allowing access to the records of his patients and for his comments, to $\mathrm{Mr} \mathrm{C} \mathrm{E} \mathrm{Rossiter} \mathrm{for} \mathrm{reading} \mathrm{the} \mathrm{radiographs,}$ and to Mrs I Ashton for her technical help.

\section{References}

Caplan, A (1953). Certain unusual radiological appearances in the chest of coal-miners suffering from rheumatoid arthritis. Thorax, 8, 29-37.

Carpenter, R G, Cochrane, A L, Gilson, J C, and Higgins, I T T (1956). The relationship between ventilatory capacity and simple pneumoconiosis in coalworkers. The effect of population section. British Journal of Industrial Medicine, 13, 166-176.

Cochrane, A L, and Higgins, I T T (1961). Pulmonary ventilatory functions of coal miners in various areas in relation to the X-ray category of pneumoconiosis. British Journal of Preventive and Social Medicine, 15, 1-11.

Cotes, J E (1975). Lung function. Assessment and Application in Medicine, 3rd edition. Blackwell, Oxford.

Gilson, J C, Hugh-Jones, P, Oldham, P D, and Mead, $F$ (1955). Lung function in coalworker's pneumoconiosis. Special Report Series MRC (London) 290.

Gough, J, Rivers, D, and Seal, R M E (1955). Pathological studies of modified pneumoconiosis in coal miners with rheumatoid arthritis (Caplan's syndrome). Thorax, 10, 9-18.

Hyatt, R E, Kistin, A D, and Mahan, J K (1964). Respiratory disease in southern West Virgina coal miners. American Review of Respiratory Disease, 89, 387-401.

ILO U/C (1971). International classification of radiographs of pneumoconiosis. Occupational Safety and Health series. International Labour Office, Geneva. 
Kilpatrick, G S, Heppleston, A G, and Fletcher, C M (1954). Cavitation in the massive fibrosis of coal worker's pneumoconiosis. Thorax, 9, 260.

McDermott, M, and McDermott, T J (1977). Digital incremental techniques applied to spirometry. Proceedings of the Royal Society of Medicine, 70, 169171.

Medical Research Council Committee on the Aetiology of Chronic Bronchitis (1965). Definition and classification of chronic bronchitis for clinical and epidemiological purposes. Lancet, 1, 775-779.

Miall, W E, Caplan, A, Cochrane, A L, Kilpatrick, G S, and Oldham, P D (1953). An epidemiological study of rheumatoid arthritis associated with characteristic chest $X$-ray appearances in coal workers. British Medical Journal, 2, 1231-1236.
Morgan, W K C, Seaton, A, Burgess, D B, Lapp, N L, and Reger, $R$ B (1972). Lung volumes in working coal miners. Annals of the New York Academy of Sciences, 200, 478-493.

Ryder, R, Lyons, J P, Campbell, H, and Gough, J 을 (1970). Emphysema in coal worker's pneumoconiosis. British Medical Journal, 3, 481-487.

Seaton, A, Lapp, N L, and Morgan, W K C (1972). Lung mechanics and frequency dependence of com- $\vec{\omega}$ pliance in coal miners. Journal of Clinical Investigation, 51, 1203-1211.

Requests for reprints to: Mr G Berry, MRC Pneumoconiosis Unit, Llandough Hospital, Penarth, South $D_{\perp}$ Glamorgan CF6 1XW. 